\title{
Thyroid remnant volume and Radioiodine ablation in Differentiated thyroid carcinoma.
}

\author{
Md. Sayedur Rahman Miah, Md. Reajul Islam, Tanjim Siddika \\ Institute of Nuclear Medicine \& Allied Sciences, Comilla
}

For Correspondence: Prof. Dr. Md. Sayedur Rahman Miah, Director, Institute of Nuclear Medicine \& Allied Sciences, Comilla Medical College Campus, Comilla. E-mail: miahmsr@hotmail.com

\begin{abstract}
Aims: The aims of the study were to determine the thyroid remnant volume and to see the effect of radioiodine ablation on thyroid remnant volume.

Methods: A retrospective analysis of seventy-one differentiated thyroid carcinoma patients treated with high dose radioiodine (I-131) for post surgical ablation of thyroid remnants were done in Institute of Nuclear Medicine \& Allied Sciences, Comilla of Bangladesh Atomic Energy Commission. Female were 60 and male were 11 with female-male ration of 5.5:1. All patients enrolled during the period from January 2001 to December 2011. The age range of the patients was 15 years to 90 years. The thyroid remnant volumes were determined by SPECT scintigraphy. High dose radioiodine (I-131) ablations were done with doses ranged from $2.77 \mathrm{GBq}$ (75mCi) to $5.55 \mathrm{GBq}$ (175 $\mathrm{mCi})$. A successful ablation was defined as the absence of activity in the thyroid bed on subsequent imaging studies.

Results: Fifty-nine patients (83.1\%) showed complete ablation and twelve (16.9\%) showed partial ablation of thyroid remnants after radioiodine therapy. The remnant thyroid volume as determined from scintigraphic images was significantly different $(p=0.048)$ between them who were completely ablated and them who were partially ablated. It was also observed that in complete ablation, $52.5 \%$ had thyroid remnant volume $<1.0 \mathrm{gm}, 40.7 \%$ had 1.1 to $2.0 \mathrm{gm}, 5.1 \%$ had 2.1 to $3.0 \mathrm{gm}$ and $1.7 \%$ had > 3.0 gm. i.e., The smaller the volume of thyroid remnant, better the response and larger the volume, the poorer the response to radioiodine.

Conclusions: Successful ablation of thyroid remnants significantly depends on their volume and the successful ablation is inversely related with thyroid remnant volume.
\end{abstract}




\section{INTRODUCTION}

Differentiated thyroid carcinoma (DTC) accounts for over $90 \%$ of all thyroid malignant tumors (1) and has an overall excellent prognosis. The therapeutic approach for a DTC usually involves total or near total thyroidectomy followed by radioiodine ablation therapy (2). Radioiodine ablation is done to ablate any remaining thyroid tissue, normal or malignant $(3,4)$. Successful ablation depends on type of surgery, thyroid remnant volume, radioactive iodine uptake (RAIU), effective half-life (EHF) of I-131 etc $(5,6)$. There are several studies on thyroid remnant volume and radioiodine ablation $(7,8,9)$. Thyroid remnant can be assessed clinically or by surgeon's notes or by imaging such as ultrasonography or scintigraphy (6). Among these, clinical assumption, surgeon's notes, ultrasonography or plannar scintigraphy is found to be inadequate (6). Tc-99m pertechnitate single photon emission computed tomography (SPECT) showed superior to planar scintigraphy in determination of thyroid remnant volume (6). The aims of this study were to determine the thyroid remnant volume by SPECT scintigraphy and to see the effect of radioiodine ablation on thyroid remnant volume.

\section{MATERIAL AND METHODS}

\section{Patient group}

The medical records of 71 patients treated for differentiated thyroid carcinoma in Institute of Nuclear Medicine \& Allied Sciences (INMAS), Comilla from January 2001 to December 2011 were reviewed retrospectively. All patients had undergone a total or near total thyroidectomy with radical neck resection (in case of neck lymph node metastases) prior to radioiodine treatment. The age, sex, histological type and lymph node involvement, thyroid remnant volume and pre treatment thyrotropin (TSH) levels were recorded in all patients.

\section{Radioiodine treatment}

In INMAS, Comilla radioiodine treatment in DTC was done on the basis of consensus on Therapy protocol for thyroid carcinoma (10). According to consensus, histopathologically proven DTC were considered for radioiodine treatment. Post operative pre-ablative assessment were done with thyroid scintigraphy with $111 \mathrm{MBq}(3 \mathrm{mCi}){ }^{99 \mathrm{~m}} \mathrm{Tc}$-pertechnitate, thyroid and neck ultrasonography with $7.5 \mathrm{MHz}$ probe and thyroid stimulating hormone (TSH) estimation were done approximately 4-6 weeks after surgery. No exogenous TSH was used in this study group. No TSH suppression was initiated until the completion of I-131 treatment. Empirically fixed high dose of radioiodine was given. Treatment doses ranged from $2.77 \mathrm{GBq}(75 \mathrm{mCi})$ to $5.55 \mathrm{GBq}$ 
$(150 \mathrm{mCi})$. The criteria used to determine the ablative dose were based on the presence or absence of lymph node and distant metastases. A $2.77 \mathrm{GBq}(75 \mathrm{mCi})$ dose was selected for patients free from lymph nodes or distant metastases and a $5.55 \mathrm{GBq}(150 \mathrm{mCi}) \mathrm{I}-131$ dose was selected for patients with cervical lymph node. All patients were hospitalized in a specially designed shielded room during treatment until exposure was less than $50 \mu \mathrm{Sv} / \mathrm{hour}$. During hospitalization, the patients were orally hydrated and instructed to chew a gum to stimulate the salivary glands for faster I-131 excretion. A whole body iodine scan (WBS) was performed on $5^{\text {th }}$ post-ablative day using a large field-of-view gamma camera equipped with high-energy parallelhole collimator. Any discrete uptake in the thyroid bed on the post-ablative scan was considered to be a remnant. Metastases were clearly identified as abnormal foci of uptake outside the thyroid bed.

\section{Follow up procedures and criteria for successful ablation}

All patients were followed up at 3 months, 6 months and after 1 year and then 6 monthly. The first follow up scan was performed after 1 year with $185 \mathrm{MBq}(5 \mathrm{mCi})$ of I-131 when TSH was $>30$ $\mathrm{mIU} / \mathrm{L}$. Raised TSH was achieved by prior withdrawal of thyroid hormone for 4-6 weeks. Radioiodine ablation was considered to be successful when there was no detectable uptake in the thyroid bed. Any focal uptake in the neck or elsewhere in the body was considered to represent treatment failure or metastases and I-131 ablation therapy was repeated until complete ablation was achieved. Palpation, ultrasound of neck, serum TSH and serum thyroglobulin were done in all patients in all follow up visit and before iodine ablation as well as during each diagnostic I131 whole body scan.

\section{RESULTS}

Total 71 patients were studied of which 60 were female and 11 were male with female: male ratio of 5.4:1 and age ranged of the patients was 15 years to 90 years. The histopathological diagnosis was papillary carcinoma in 58 patients $(81.7 \%)$ and follicular carcinoma in 13 patients $(18.3 \%)$. Of 58 papillary carcinoma, $15(25.8 \%)$ had papillary carcinoma with lymph node metastasis. Of 13 follicular carcinoma cases, 2 (15.4\%) were follicular with lymph node metastasis. There was no distant metastasis case in the studied group. From the study, it was seen that 59 patients (83.1\%) showed complete ablation and $12(16.9 \%)$ showed partial ablation of thyroid remnants. The radioiodine (I-131) dose used in complete ablation and partial ablation were $88.49 \pm 21.62$ $\mathrm{mCi}$ and $87.91 \pm 28.24 \mathrm{mCi}$ respectively. The thyroid remnant volume in complete ablation and 
partial ablation were $1.3 \pm 0.7 \mathrm{gm}$ and $2.0 \pm 0.8 \mathrm{gm}$ respectively (Table-1). It was also seen that in complete ablation, $52.5 \%$ had thyroid remnant volume $<1.0 \mathrm{gm}, 40.7 \%$ had 1.1 to $2.0 \mathrm{gm}$, $5.1 \%$ had 2.1 to $3.0 \mathrm{gm}$ and $1.7 \% \mathrm{had}>3.0 \mathrm{gm}$. (Table-2).

Table-1: Clinical characteristics of patients in whom complete and partial ablation of thyroid remnants achieved with I-131.

$\begin{array}{lcc}\text { Clinical characteristics } & \text { Complete ablation } & \text { Partial ablation } \\ \text { Age (Years) } & 34 \pm 12 & 34 \pm 13 \\ \text { Sex Male-11 } & 8 & 3 \\ \text { Female-60 } & 51 & 9 \\ \text { Histological type } & & \\ \quad \begin{array}{l}\text { Papillary } \\ \text { Papillary mets }\end{array} & 12 & 6 \\ \quad \text { Follicular } & 8 & 3 \\ \quad \text { Follicular mets } & 2 & 0 \\ \text { Remnant thyroid vol (gm) } & 1.3 \pm 0.7 & 2.0 \pm 0.8 \\ \text { Post-operative TSH (mIU/L) } & 74.65 \pm 12.47 & 77.95 \pm 9.56 \\ \text { I-131 dose (mCI) } & 88.49 \pm 21.62 & 87.91 \pm 28.24\end{array}$

Table-2: Thyroid remnant volume and success of radio ablation

$\begin{array}{lcc}\begin{array}{c}\text { Thyroid remnant volume } \\ \text { gram }\end{array} & \begin{array}{c}\text { Complete ablation } \\ \text { n- } 59\end{array} & \begin{array}{c}\text { Partial ablation } \\ n-12\end{array} \\ <1.0 & 31(52.5 \%) & 1(8.3 \%) \\ 1.1-2.0 & 24(40.7 \%) & 6(50 \%) \\ 2.1-3.0 & 3(5.1 \%) & 4(33.3 \%) \\ >3.0 & 1(1.7 \%) & 1(8.3 \%)\end{array}$




\section{DISCUSSION}

Radioiodine treatment for thyroid remnant ablation has established itself in the management of differentiated thyroid carcinoma. Thyroid remnant volume is one of the predictor of complete ablation $(8,9)$. There are several ways to determine thyroid remnant volume (6). In this study, post-surgery thyroid scan with Single Photon Emission Computed Tomography (SPECT) employing Tc-99m-pertechnitate was used for determination of thyroid remnant volume. Regarding the dose of radioiodine for thyroid remnant ablation, no consensus has been reached as to optimal required dose of I-131 (9). Comparable results have been reported by different centres using empirical High dose and Low dose for ablation (4). In this study empirically fixed high dose radioiodine was used. From the study, it has been observed that complete thyroid remnants ablation occurred in $83.1 \%$ cases and partial thyroid remnants occurred in $16.9 \%$ cases. Mean thyroid remnant volume of complete ablation was $1.3 \pm 0.7 \mathrm{gm}$ and mean thyroid remnant volume of partial ablation was $2.0 \pm 0.8$ gm which is statistically significant $(\mathrm{P}<0.048)$. Regarding the ablative dose of radioiodine, it was seen that in complete ablation, the mean dose was $88.49 \pm 21.62 \mathrm{mCi}$ and in partial ablation, the mean dose was $87.91 \pm 28.24 \mathrm{mCi}$ which is statistically not significant. Thus thyroid remnant volume is the critical factor for achieving ablation of thyroid remnant. From the study, it was also found that of complete thyroid remnant ablation, $52.5 \%$ had thyroid remnant volume $<1.0 \mathrm{gm}, 40.7 \%$ had 1.1 to $2.0 \mathrm{gm}, 5.1 \%$ had 2.1 to $3.0 \mathrm{gm}$ and $1.7 \%$ had $>3.0 \mathrm{gm}$. i.e,. The smaller the volume of thyroid remnant, better the response and larger the volume, the poorer the response to radioiodine ablation therapy. Findings of this study are close to other researchers. Maxon et al have indicated that the greatest success of I-131 ablation occurred when less than 2 gm of thyroid tissue remained after thyroidectomy (6). Samuel AM and Rajashekharrao B found that $87.3 \%$ ablation achieved in tissues of mass less than $5 \mathrm{gm}$ (8). In partial ablation cases, percentage of partial ablation does not correlate with thyroid remnant volume that may be due to very small sample size. Further study needed with large sample size to find out the relation of partial ablation with thyroid remnant volume.

\section{CONCLUSIONS}

Thyroid remnant volume is primarily responsible for successful ablation and the successful ablation is inversely related with thyroid remnant volume. 


\section{REFERENCES}

1. Maussier ML, Danese D, D'Errico, et al. Clinical laboratory follow up in differentiated thyroid carcinoma. Rays 2000; 25:239-44.

2. BeierWaltes WH, Rabbani R, DmuchowsKic, et al. An analysis of ablation of thyroid remnants with I-131 in 511 patients from 1947-1984; experience at university of Michigan. J. Nucl. Med. 1984: 1287-92.

3. Mazzaferri EL,. Thyroid remnant 131-I ablation for papillary and follicular thyroid carcinoma. Thyroid 1997;7:265-271.

4. Creutzig H. High or low dose radioiodine ablation of thyroid remnants? Eur J Nucl Med 1987; 12: 500-5002.

5. Akther R, Hossain S, Rashid H, Afroz S. Outcome of differentiated thyroid carcinoma following surgery and radioiodine ablation therapy- A study on 269 patients in CNMU, Dhaka. Bangladesh J Nucl Med. 2006; 9(2): 114-117.

6. Nadig MR, Pant GS, Bal C. Usefulness of $99 \mathrm{mTc}$-pertechnetate single -photon emission computed tomography in remnant mass estimation of postsurgical patients of differentiated thyroid cancer during internal dosimetry. Nucl Med Communications 2008; 29: 808-814.

7. Maxon HR, Englaro EE, Thomas SR et al. Radioiodine -131 therapy for well differentiated thyroid cancer- a quantitative radiation dosimetric approach. Outcome and validation in 85 patients . J Nucl Med 1992;33:1132-1136.

8. Samuel AM, Rajashekharrao B. Radioiodine Therapy for Well-Differentiated Thyroid Cancer: A quantitative Dosimetric Evaluation for Remnant Thyroid Ablation After Surgery. J Nucl Med 1994; 35(12): 1994-1950.

9. Arslan N, Ilgan S, Serdengecti M, Ozguver MA, Bayhan H et al. Post-surgical ablation of thyroid remnants with high dose I-131 in patients with differentiated thyroid carcinoma. Nucl Med Communication 2001; 22:1021-1027.

10. AlamFaridul, Islam ASMM, Karim MA. Therapy Protocol for Thyroid Carcinoma and Thyrotoxicosis with I-131 Adopted in the National Workshop on Management of Thyroid Cancer \& Thyrotoxicosis by Nuclear Medicine Technique- A Consensus Report. Bangladesh J Nucl Med 2002; 5(2): 39-42. 